\title{
Ein Apparat zum selbstthätigen Abschliessen der Gasflamme
} nach einer gewünschten Zeit, den J. Hertkorn*) construirt hat, besteht aus einem in die Gasleitung eingeschalteten Zwischengefäss, aus welchem das Gas durch eine im Stopfen verschiebbare, ziemlich lange Glasröhre nach dem zum Brenner führenden Schlauche gelangt. In diese Flasche fliesst aus einer höher stehenden Wasser mit einer bekannten Geschwindigkeit ein. Sobald das Niveau des letzteren das untere Ende des Gasaustrittsrohres erreicht hat, schliesst es letzteres ab und die Lampe erlischt. Damit der Wasserzufluss nicht durch den Gasdruck gehindert wird, stehen das obere Ende der Zwischenflasche und der das zufliessende Wasser enthaltenden, oben geschlossenen Flasche durch Röhren mit einander in Verbindung.

Als Unterlage beim Abwägen von Substanzen empfiehlt $\mathrm{H}$. Schweitzer**) Zylonit, ein von der American Zylonite Company in Zylonite Mass. aus nitrirter Cellulose, Camphor und Alkohol hergestelltes Product, welches in dünnen, durchsichtigen oder pauspapierähnlichen Bogen in den Handel kommt. Die Dicke des Bogens ist die dünnen Cartonpapiers. Das Zylonit-Papier ist wasserdicht und hat den Vortheil, dass man bei quantitativen Wägungen die feste Substanz abwaschen kann. Es kann mehrmals benutzt werden, ist so gut wie unzerreissbar und unter gewöhnlichen Bedingungen säure- und alkalibeständig; nur beim Gebrauch organischer Lösungsmittel ist Vorsicht anzuwenden. Ein Hauptvortheil des Zylonit-Papiers liegt noch darin, dass es sein Gewicht nur sehr langsam ändert. Es verbrennt etwas energischer als gewöhnliches Papier.

Einen Apparat zur Bestimmung des Schmelzpunktes von Fetten, wie er im Laboratorium der Handelsbörse in Paris gebraucht wird, beschreibt Muter***). Die Vorrichtung beruht auf dem zuerst von Loewe $\dagger$ ) angegebenen Principe und weicht nur in der äusseren Anordnung von dem Apparate dieses Autors ab.

Der Haupttheil derselben besteht aus einer U-förmigen Röhre, in deren einen Schenkel ein Platindraht, der mit einer elektrischen Klingel in Verbindung steht, so weit eingetaucht ist, dass er mit seinem Ende unter die Biegung der Röhre reicht. Der andere Schenkel der Röhre

*) Chemiker-Zeitung 13, 1305.

**) Chemiker-Zeitung 14, 698.

***) The Analyst 15, 85.

†) Vergl. diese Zeitschrift 11, 211. 